\title{
Updates in hybrid AF ablation: a hybrid approach to surgical epicardial ablation and cather endocardial ablation in persistent atrial fibrillation
}

\author{
Young Keun $\mathrm{On}^{1 *} \mathbb{D}$ and Dong-Seop Jeong ${ }^{2}$
}

\begin{abstract}
Atrial fibrillation (AF) is the most common and increasing cardiac arrhythmia. AF increases thromboembolic events and hospitalizations and deteriorates quality of life. The mechanism of AF is not completely understood. James Cox proposed a concept of Maze procedure in 1987 which was based on a surgical ablation lesion for electrical conduction pathway. Although surgical ablation offers a higher success rate, it should be performed with minimally invasive techniques because of its high invasiveness. Haissaguerre et al. identified potential sources of AF in the pulmonary veins as triggers and developed the percutaneous catheter ablation as the treatment strategy for paroxysmal AF refractory to pharmaceutical therapy. The atrial remodeling occurs electrically and structurally in persistent or longstanding persistent AF, and the catheter ablation and surgical ablation have variable success rates. Persistent or longstanding persistent AF presents a major challenge. Despite continuous improvements, catheter-based procedures have shown relatively far from satisfactory outcomes and may need to be repeated to achieve sinus rhythm. A hybrid approach consisting of the sequential combination of a surgical minimally invasive epicardial ablation and a transvenous catheter endocardial ablation would be an alternative option that supplements the limitations of endo- and epicardial strategies. Close cooperation between cardiac surgeons and electrophysiologists for optimal selection of patients and management for arrhythmia recurrence seems suggestible for persistent or longstanding persistent AF.
\end{abstract}

Keywords: Ablation, Atrial fibrillation (AF), Hybrid approach, Surgical ablation, Thoracoscopic, Catheter ablation

\section{Introduction}

Atrial fibrillation (AF) is the most common and increasing cardiac arrhythmia. AF increases the risk of thromboembolic events and hospitalizations and deteriorates quality of life $[1,2]$.

The mechanism of AF is not completely understood. Increasing age may contribute to increasing incidence

\footnotetext{
*Correspondence: yk.on@samsung.com

${ }^{1}$ Division of Cardiology, Department of Internal Medicine, Heart Vascular and Stroke Institute, Samsung Medical Center, Sungkyunkwan University School of Medicine, 81 Irwin-ro, Gangnam-gu, Seoul 06351, Republic of Korea

Full list of author information is available at the end of the article
}

and prevalence of AF as well as hypertension, diabetes mellitus, structural heart disease or obesity. Antiarrhythmic treatment has lower efficacy and various adverse events [1].

James Cox proposed and developed a surgical ablation technique called the Maze procedure in 1987 [3]. The Maze procedure is technically challenging and highly invasive and requires a full sternotomy and cardiopulmonary bypass and cardiac arrest. Frequent complications are bleeding and complete atrioventricular block. The Maze procedure was revealed very effective, but was not widely accepted because of its very invasiveness and complexity [4]. The lesion set of surgical ablation was

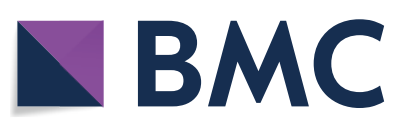

(c) The Author(s) 2021. Open Access This article is licensed under a Creative Commons Attribution 4.0 International License, which permits use, sharing, adaptation, distribution and reproduction in any medium or format, as long as you give appropriate credit to the original author(s) and the source, provide a link to the Creative Commons licence, and indicate if changes were made. The images or other third party material in this article are included in the article's Creative Commons licence, unless indicated otherwise in a credit line to the material. If material is not included in the article's Creative Commons licence and your intended use is not permitted by statutory regulation or exceeds the permitted use, you will need to obtain permission directly from the copyright holder. To view a copy of this licence, visit http://creativecommons.org/licenses/by/4.0/. 
modified in the Maze III or IV procedure, in which the endocardial biatrial lesion sets are accomplished with bipolar radiofrequency or cryoablation through minithoracotomy or sternotomy in case of combination with cardiac surgery such as coronary artery bypass graft or aorta surgery [5]. Guideline recommends the surgical ablation for AF patients undergoing other cardiac surgery as class IIA [1].

Haissaguerre et al. identified potential sources of AF in the pulmonary veins (PVs) as triggers and developed the treatment option of radiofrequency catheter ablation (RFCA) of the PVs [6].Percutaneous RFCA is now the preferred treatment strategy for paroxysmal AF refractory to antiarrhythmic therapy [7]. The success rate of RFCA for paroxysmal AF is good. However catheter ablation for persistent $\mathrm{AF}$ remains challenging and the results are far from satisfactory. Also the success rate of catheter ablation declines with time. The substrate in paroxysmal AF could be associated with ectopic triggers from the PVs $[8,9]$. However, as the AF duration increases, the mechanisms for formation and maintenance of AF could involve many factors consisting of triggers from the PVs, right atrium, autonomic ganglionated plexi (GP) and the posterior wall of the left atrium (LA) [7]. While pulmonary vein isolation (PVI) using endocardial catheter ablation has been successful in paroxysmal AF, the results have been more limited in patients with persistent or longstanding persistent AF where extra-pulmonary venous foci are increasingly noted in the initiation and maintenance of AF. Success rates for paroxysmal AF ablation were noted high, but the recurrence rates usually depended on the AF duration and AF ablation revealed lower success rates for persistent AF and even showed poor outcomes for long-standing persistent AF.

The pathophysiological mechanisms for persistent or longstanding persistent AF are more complex than those for paroxysmal AF. The approach of PVI alone is not effective for persistent or long-standing persistent AF. Extra-PV substrate of AF consists of the left atrial appendage (LAA), posterior wall of left atrium, ligament of Marshall (LOM), coronary sinus, crista terminalis, and superior vena cava $[10,11]$. Atrial electrical and structural remodeling occurs in persistent or longstanding persistent $\mathrm{AF}$ and it is likely that the persistent $\mathrm{AF}$ population requires more extensive ablation such as the Cox Maze lesion set. There is a progressive AF recurrence after catheter ablation in longer follow-up of persistent or longstanding persistent AF. Patients undergoing multiple ablation procedures might had increased risk of complications, cost, and radiation exposure.

Surgical Cox Maze ablation showed high success rate, but its high invasiveness limits widespread acceptance. Minimally invasive surgical techniques reappear the maze-like surgical ablation. Minimally invasive surgical ablation shows very good effectiveness and safety in the treatment of AF. A meta-analysis [12] including 7,624 patients with persistent AF revealed that AF freedom at 12 months was $69 \%$ after surgical ablation and $51 \%$ after catheter ablation. More severe procedural adverse events occurred with surgical ablation than with catheter ablation. So minimally invasive surgical techniques reveal high success rate in maintenance of sinus rhythm and more complications. In the 2020 European Society of Cardiology AF guideline, both surgical and catheter ablation should be suggested as therapeutic options for persistent or long-standing persistent AF (IIA) [1].

Catheter ablation and minimally invasive surgical ablation show variable success rates and complication rates, due to the various characteristics of AF, follow-up durations, different procedural methods, and diverse experienced operators. Close cooperation between cardiac surgeons and electrophysiologists for optimal selection of patients and treatment for recurrence of arrhythmia should be recommended for persistent or long-standing persistent AF [1].

In this review, we would like to review and update the stand-alone minimally invasive surgical epicardial ablation, catheter endocardial ablation, and the hybrid approach of surgical and catheter ablation in patients with persistent or long-standing persistent AF.

\section{Surgical procedure of totally thoracoscopic ablation (TTA)}

The strategy of "totally thoracoscopic ablation" is a videoassisted thoracoscopic surgical ablation without the aid of cardiopulmonary bypass or the Da Vinci system [13]. This technique is performed via three holes (two 5-mm ports and one $10-\mathrm{mm}$ port) bilaterally. A hole in the fourth intercostal space at the mid-axillary line and one hole in the third intercostal space at the anterior axillary line and one hole in the sixth intercostal space at the mid-axillary line were used. After pericardial tenting, an AtriCure Isolator Transpolar Clamp (AtriCure, Inc.) is positioned for ablation of PV antrum (Fig. 1a-c). Superior and inferior ablation lines are produced epicardially using a linear pen device (MLP, AtriCure, Inc.).

As described by Cox J, mitral isthmus ablation, cavotricuspid-isthmus (CTI) ablation, intercaval line, and transverse line are essential elements of Cox Maze III/IV procedures to prevent macroreentry. The ablation lines can be performed endocardially or epicardially via Cox Maze III/IV under cardiopulmonary bypass with right minithoracotomy. Intercaval superior vena cava (SVC) inferior vena cava (IVC) line is the right sided procedure of surgical Maze procedure and epicardial thoracoscopic approach is used for right sided Maze procedure [5]. 

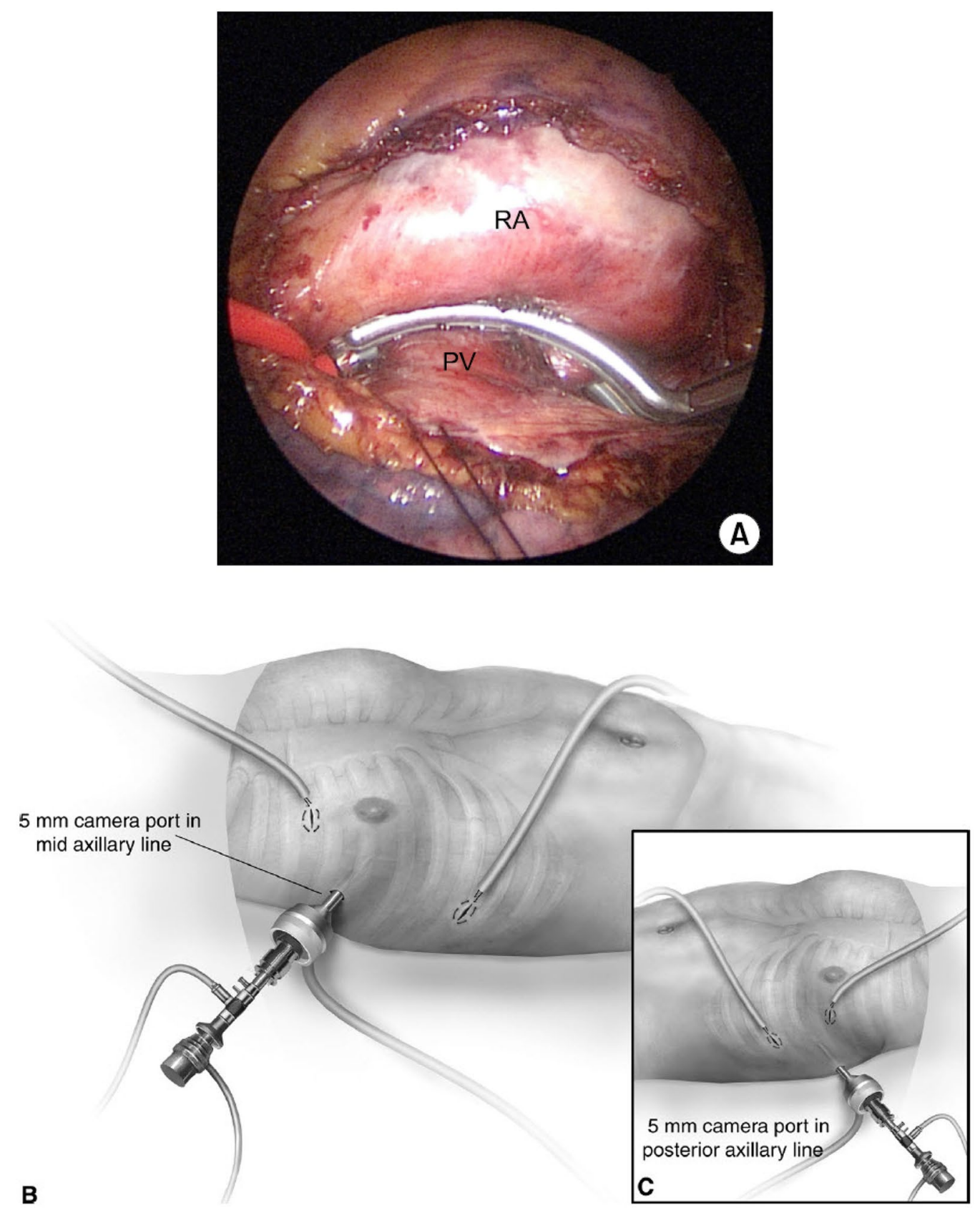

Fig. 1 a Thoracoscopic view of totally thoracoscopic ablation of atrial fibrillation. PV antrum isolation is performed by applying bipolar radiofrequency energy (AtriCure, Inc.). b, c Totally thoracoscopic ablation of atrial fibrillation. This technique is performed via three holes (two 5-mm ports and one 10-mm port) bilaterally

Mitral isthmus ablation and CTI ablation could not be done with the thoracoscopic AF ablation technique.

GP are subsequently ablated in the epicardial fat pad at anterior side of the right superior and inferior PVs, inferior side of the right inferior PV and the LA posterior wall. After PV and the GP ablation, the LOM is dissected and ablated. LAA is excised using thoracoscopic stapler (Ethicon Endo-Surgery Inc., Cincinnati, OH, USA) (Fig. 2). 


\section{Lesions Set of Totally Thoracoscopic Ablation}

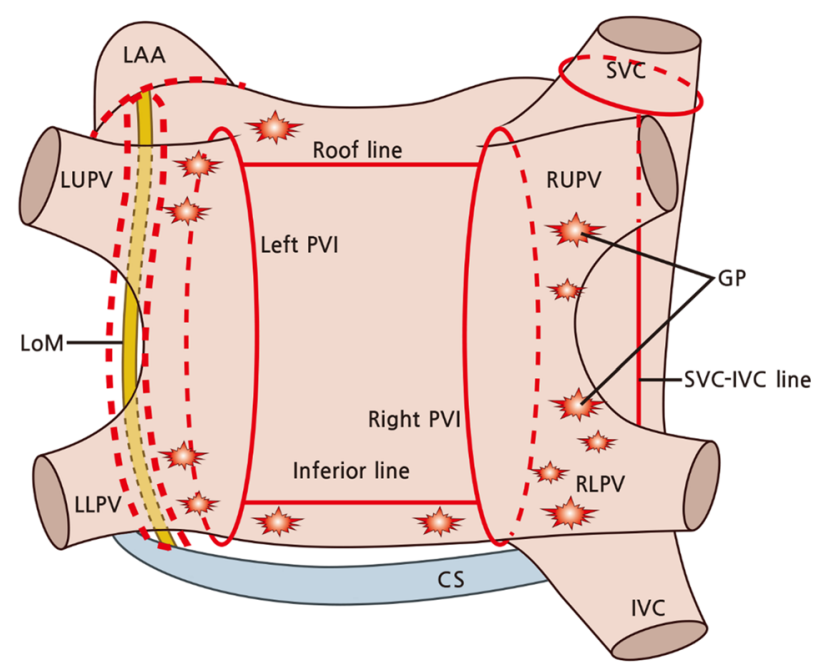

TTA, totally thoracoscopic ablation; LAA, left atrial appendage; LUPV, left upper pulmonary vein; LLPV, left lower pulmonary vein; RUPV, right upper pulmonary vein; $R L P V$, right lower pulmonary vein; $P V I$, pulmonary vein isolation; $L O M$, ligament of Marshall; GP, ganglionated plexus; SVC, superior vena cava; $I V C$, inferior vena cava; $C S$, coronary sinus.

Fig. 2 Lesions set of totally thoracoscopic ablation of atrial fibrillation

\section{Radiofrequency catheter ablation (RFCA) procedure}

An electrophysiological study (EPS) is performed after TTA [14]. A Thermocool catheter (Biosense Webster) for ablation and a Lasso mapping catheter are introduced in the LA. PV antral ablation for electrical PV isolation, cavotricuspid-isthmus (CTI) ablation, mitral isthmus ablation line, roof ablation line, atrial septal ablation, or SVC isolation could be performed.

\section{The stand-alone minimally invasive surgical procedure for AF}

The surgical Maze procedure needs cardiopulmonary bypass and reveals high complication rate comparing to catheter technique. Minimally invasive surgical techniques find the similar effects of the Cox Maze procedure, but with less complications. The TTA approach adopts a circular atrial ablation lesion set around pulmonary veins.

In a meta-analysis of minimally invasive surgical ablation procedures, the success rate in patients with paroxysmal AF was $75 \%$ at 12 months and $67 \%$ in persistent $\mathrm{AF}$, and $43 \%$ in long-standing persistent $\mathrm{AF}$ [15].

A clinical trial including 125 patients compared surgical and catheter ablation. The surgical ablation demonstrated higher efficacy rate (65\% vs. $36 \%)$ at 1 year and at mean 7 -year follow-up (44\% vs. 13\%) [16, 17]. However, longer duration of hospitalization was noted and the adverse events seem to be more frequent in surgical ablation than catheter ablation [18-21].

Kim et al. [20] published a meta-analysis of three randomized controlled trials and two retrospective studies comparing the efficacy and safety of TTA versus RFCA. The rate of freedom of atrial arrhythmia without antiarrhythmic drugs was confirmed higher after TTA than RFCA during 12 months of follow-up, and higher rate of side effects during the post-procedural period was noted in the TTA group compared in the RFCA group.

Phan et al. [21] published a meta-analysis of surgical minimally invasive thoracoscopic ablation in comparison with catheter ablation for sinus rhythm restoration. The success rates were $74.4 \%$ vs. $51.1 \%$ respectively at 12-month in persistent AF. However, the rate of major complications showed higher in the thoracoscopic ablation group (28.2\% vs $7.8 \%)$, such as pleural effusion and pneumothorax.

Considering the risk-benefit ratio of surgical vs catheter ablation, thoracoscopic approach should be suggested for patients with previous failed catheter ablation or with a high risk of catheter-ablation failure. The advantage of surgical ablation could be the surgeon's ability to gain direct access to the epicardial structures such as the ligament of Marshall and GP. Direct visualization enables to avoid complications of the phrenic nerve and the esophagus. 
Berger WR et al. [12] published a meta-analysis revealing that minimally invasive surgical ablation is associated with higher AF freedom in persistent AF patients (AF freedom at 12 months: $69 \%$ after surgical ablation vs $51 \%$ after catheter ablation). However, severe procedural adverse events were noted more frequent with surgery than with catheter ablation.

We evaluated the effect of previous catheter ablation on the midterm outcomes of TTA in AF patients (persistent AF; $\mathrm{n}=264,80 \%$ ). The AF recurrence free rate at 5 years was $55.3 \%$ in the previous catheter ablation group compared with $55.7 \%$ in the de novo TTA group. [22].

\section{The hybrid approach}

If permanent PVI is the ablation strategy, different techniques such as combined approach of surgical and catheter ablation might be needed to improve long-term efficacy, and hybrid approach could show better results [23]. Surgical epicardial ablation has been shown to increase transmurality of the ablation lesions and to eliminate epicardial targets for AF, such as the LAA, the GP and the LOM. Theoretically combining the epicardial approach with endocardial ablation into a one-stop procedure that includes validation of the ablation lines and modification of the residual AF substrate may increase long-term procedural success rates. A hybrid approach of the sequential procedures of TTA and RFCA is an alternative strategy that supplements the limitations of endoand epicardial ablations [14].

We evaluated the effect of the hybrid ablation (a staged RFCA procedure during the same hospitalization after TTA) compared with RFCA alone. There was no significant difference in recurrence of any atrial arrhythmia during median 2.1-year follow-up between the hybrid and RFCA alone (32.5\% vs. $35.7 \%)$. But the AF recurrence was lower in the hybrid group than in the RFCA alone group ( $29.6 \%$ vs $34.9 \%$, HR: $0.53 ; P=0.046)$. [14] The hybrid AF ablation strategy in our institution was not the procedure in a hybrid operating room in a single hospitalization.

The timing of the hybrid approach should be a topic of discussion. Performing the two procedures during a single session reduces repeated hospitalization, but prolongs the duration of procedure. We examined the effect of postprocedural electrophysiological study after TTA. Persistent AF patients were randomized into 2 groups, the hybrid group and the TTA only group. Electrophysiological confirmation was studied at 4 or 5 day after TTA. In hybrid group, additional ablation was performed in $23 \%$. Normal sinus rhythm was noted similar in both groups at one year [24]. Having a 1- to 3-month interval between the two stages leads the ablation lesions to recover, which could reveal gaps in ablation line.

Asmundis et al. [25] reported the results of TTA followed by simultaneous RFCA. The success rate was $67.2 \%$ at a 23.1 months after hybrid procedure and the overall freedom from AF reached $79.7 \%$ after redo RF procedures.

Mahapatra et al. [26] presented a sequential approach during the same hospitalization in patients with persistent or long-standing persistent AF and enlarged left atrium. After 20.7 months of follow-up, $86.7 \%$ of hybrid patients and $53.3 \%$ of catheter-alone patients, were free of any atrial arrhythmia without anti-arrhythmic drugs (AAD) $(p=0.04)$. On AAD, $93.3 \%$ of hybrid patients showed free of any atrial arrhythmia recurrence, compared to $56.7 \%$ catheter-alone patients $(p=0.01)$.

Another hybrid approach is the convergent transdiaphragmatic procedure with standard laparoscopic techniques and endocardial RFCA [27, 28]. The operator could not approach superior region of PVs and the inferior part of the right PVs thru trans-diaphragmatic approach because of the anatomy of pericardial reflections. So the endocardial RFCA is mandatory to complete the electrical isolation of pulmonary veins in a hybrid convergent procedure.

A convergent trial demonstrated the successful results in treating persistent and longstanding persistent AF patients [28]. Endocardial mapping and RFCA with diagnostic confirmation of procedural success complemented the surgical creation of epicardial linear lesions. After convergent procedures, $88 \%$ of patients were in sinus rhythm at 12 -month follow-up and $87 \%$ at 24 months. The median AF burden recorded with implantable loop recorder was $0.1 \%$ at 24 months with $87 \%$ of patients demonstrating AF burden less than 3\%.

Gersak et al. [29] reported that the convergent procedure was a safe and efficacious treatment option for persistent and long-standing persistent AF. The singleprocedure maintenance of sinus rhythm was $76 \%$ at 12 months and $52 \%$ were in sinus rhythm without antiarrhythmic drugs.

A meta-analysis [30] suggested that hybrid treatment using mini-thoracotomy access showed superior outcome in freedom of atrial arrhythmia after follow-up duration (odds ratio $[\mathrm{OR}]=6.67$ ).

But hybrid treatment through either mini-thoracotomy or trans-diaphragmatic/subxiphoid approach had limitation such as longer procedure time and duration of hospitalization than catheter ablation.

A systematic review in persistent or long-standing persistent AF found that a hybrid approach showed a higher success rate of freedom from arrhythmias at 12 months 
or longer compared with AF catheter ablation $(70.7 \%$ vs 49.9\%, P < 0.001). [31] Hybrid ablations had higher rate of complications (13.8\% vs $5.9 \%)$. Large-scale randomized controlled trials comparing both strategies are needed.

In a hybrid approach of thoracoscopic epicardial procedure with Cobra-Fusion system and transcatheter mapping with endocardial touch-up of gaps to persistent AF with dilated atria, [32] 92\% of patients underwent a second-stage endocardial procedure after a mean of 2.2 months and touch-up ablation of surgical lesions was performed in $54 \%$ of patients and a CTI ablation was applied in $17 \%$ of patients. At 2 years, $65 \%$ of patients were in sinus rhythm without the use of antiarrhythmic drugs or electrical cardioversion and $82 \%$ were in sinus rhythm allowing antiarrhythmic drugs or electrical cardioversion. The box was isolated during the endocardial procedure in less than half of the patients (46\%), therefore, the Cobra-Fusion technique is not very effective in making durable transmural lesions but demonstrates the added value of a hybrid approach.

Electrophysiological follow-up 2-3 months after surgical TTA to deliver a circumferential lesion set anterior to the pulmonary veins in an attempt to isolate the posterior LA revealed that the box isolation was incomplete in $60 \%$ and box isolation was successfully achieved with additional catheter ablation in $89 \%$ of those patients [33]. Typical gap locations were the anterior-superior part of the superior PVs and the roofline.

In our institution, EPS was performed for recurrent atrial tachyarrhythmia at least 3 months after the TTA procedure and $50 \%$ of the recurred patients revealed AF as recurrent form of arrhythmia. Non-PV related arrhythmias were confirmed in half of recurred patients. Gaps in right PVs were frequently noted at the posterior ridge [34].

Tan et al. [35] reported that subsequent endocardial mapping showed that $28 \%$ of the patients had incomplete isolation of the right superior PVs and 6\% patients had incomplete ablation lesions at the roof of the left atrium. The left PVs were isolated in all patients. By closing the gaps along the designated surgical lines, sinus rhythm was restored in 3 additional patients.

The different outcome of the hybrid procedure comparing with catheter ablation could be explained by a longlasting isolation of the PVs after bipolar radiofrequency clamping of the PVs, epicardial clipping of the LAA and the add-on possibility of an endocardial touch-up [33].

A study characterizing the recurrence of arrhythmia after hybrid ablation for patients with persistent AF was reported. Persistent AF patients received hybrid procedures of endocardial catheter ablation and a small midline surgical approach of the posterior LA wall and were followed for a mean of 25 months. Of patients with recurrence of arrhythmia, 53\% were in atrial flutter and $47 \%$ were in AF. Half of ablations for atrial flutter following the hybrid procedure ablated the mitral isthmus [36].

\section{Rhythm monitoring after ablation}

Holter monitoring is the mostly used method of rhythm monitoring; however, the monitoring is restricted by a relatively short duration. The guidelines of the European Society of Cardiology recommend longer period monitoring [7].

Oral anticoagulation therapy should be recommended after the ablation regardless of rhythm outcome in AF patients depending on the stroke risk factors in current guidelines [1].

\section{Left atrial appendage (LAA) exclusion}

The LAA has been revealed as a trigger of AF and regarded as a source thromboembolism.

Propensity score-matched analysis of LAA electrical isolation using a registry database of catheter ablation for nonparoxysmal AF reported that LAA electrical isolation was associated with significantly higher freedom from recurrence of atrial arrhythmia in patients with persistent and long-standing persistent $\mathrm{AF}$ and a higher risk of thromboembolic events [37]. Overall success from all-atrial arrhythmia recurrence without antiarrhythmic drugs in patients who underwent LAA electrical isolation was $68.9 \%$ vs. $50.2 \%$ in those who underwent standard ablation alone at the 5 -year follow-up $(P<0.001) .70 \%$ patients in the LAA electrical isolation group remained on oral anticoagulation at 5 -year follow-up vs. $39.7 \%$ in the non-LAA electrical isolation group. In patients who were off-oral anticoagulation thromboembolic events occurred in $9.1 \%$ in the LAA electrical isolation group and $1.2 \%$ in the non-LAA isolation group at 5 -year follow-up $(P<0.001)$.

The LAA reflects for about $90 \%$ of the clots in nonvalvular AF patients and one of the advantages of surgical ablation is the concomitant exclusion of the LAA. The recommendation for LAA management from the Society of Thoracic Surgeons is that LAA excision or exclusion is reasonable for patients with surgical ablation for AF to prevent longitudinal thromboembolic morbidity (Class IIA) [38]. The thoracoscopic approach thru the chest wall reveals direct access to the LAA. LAA occlusion was performed during cardiac surgery with the use of any of the following techniques: amputation and closure, stapler closure, double-layer linear closure from within the atrium during mini-thoracotomy, or closure with an approved surgical occlusion device. 
It remains unclear whether LAA occlusion can replace anticoagulation because of a lack of research directly comparing oral anticoagulation with LAA occlusion. Less invasive surgical options, either standalone, hybrid, or convergent, could be helpful in specific situations.

In patients with a previous stroke and a high risk of bleeding (mean $\mathrm{CHA}_{2} \mathrm{DS}_{2}$-VASc; 4.2, and HAS-BLED scores; 3.3) who underwent thoracoscopic LAA excision and AF ablation and were followed up for 2 years, all patients discontinued oral anticoagulation therapy after the surgical procedure and the annual rate of total thromboembolism was $2.05 \%$ and the rate of successful AF ablation without AF recurrence was 76.3\% [39]. The event rate of thromboembolism in this secondary prevention group was low even without oral anticoagulation. Therefore, thoracoscopic LAA excision plus AF ablation may be a promising approach for the high-risk AF patients.

In the recently published LAAOS III trial, concomitant LAA occlusion performed at the time of cardiac surgery would reduce the risk of ischemic stroke among patients with AF receiving usual care including anticoagulation. [40] The mean age was 71 years and the mean $\mathrm{CHA}_{2} \mathrm{DS}_{2}$-VASc score was 4.2 and they were followed for a mean of 3.8 years. $76.8 \%$ of the population continued to receive oral anticoagulation and stroke or thromboembolism occurred in $4.8 \%$ in the LAA occlusion group and $7.0 \%$ in the no-LAA occlusion group (HR: $0.67 ; \mathrm{P}=0.001$ ). There were no significant difference of the incidence of perioperative bleeding, heart failure, or death between the groups. Whereas anticoagulation reduces the risk of stroke by approximately two-thirds, concomitant LAA occlusion reduced the risk of stroke by approximately one-third. This has important implications for the use of non-pharmacologic therapies to prevent thromboembolic stroke.

Stand-alone LAA excision has also been used for stroke prevention in nonvalvular AF patients [41]. Follow-up results for 198 patients over a mean duration of 48 months showed that 2 patients developed cardiogenic thromboembolisms (0.25 events per 100 patient-years).

There are no concluding large-scale data on the efficacy of surgical ablation on stroke as a stand-alone procedure or in concomitant LAA exclusion, so oral anticoagulation therapy should be considered after the procedure in AF patients with stroke risk factors in current guidelines [1].

In addition to the potential benefit on stroke or thromboembolism, electrical isolation following LAA clipping, stapling or resection could prevent triggers originating from the LAA and allow mass reduction of the AF substrate, which can improve the maintenance of sinus rhythm $[11,42]$.

\section{Conclusions}

A hybrid procedure of surgical epicardial ablation and endocardial catheter ablation would be an alternative option that supplements the limitations of epi- and endocardial approaches. Close cooperation between cardiac surgeons and electrophysiologists for optimal selection of patients and management for arrhythmia recurrence, seems suggestible for persistent or longstanding persistent AF.

\section{Abbreviations \\ AAD: Antiarrhythmic drug; AF: Atrial fibrillation; CTI: Cavotricuspid-isthmus; EPS: Electrophysiological study; GP: Ganglionated plexi; HFS: High-frequency stimulation; IVC: Inferior vena cava; LA: Left atrium; LAA: Left atrial appendage; LOM: Ligament of Marshall; PV: Pulmonary vein; PVI: Pulmonary vein isolation; RFCA: Radiofrequency catheter ablation; SVC: Superior vena cava; TTA: Totally thoracoscopic ablation.}

\section{Acknowledgements}

Not applicable.

Authors' contributions

All authors read and approved the final manuscript.

Funding

Not applicable.

Availability of data and materials

Not applicable.

\section{Declarations}

Ethics approval and consent to participate

Not applicable.

Consent for publication

Not applicable.

\section{Competing interests}

The authors declare that they have no competing interests.

\section{Author details}

${ }^{1}$ Division of Cardiology, Department of Internal Medicine, Heart Vascular and Stroke Institute, Samsung Medical Center, Sungkyunkwan University School of Medicine, 81 Irwin-ro, Gangnam-gu, Seoul 06351, Republic of Korea. ${ }^{2}$ Department of Thoracic and Cardiovascular Surgery, Heart Vascular and Stroke Institute, Samsung Medical Center, Sungkyunkwan University School of Medicine, Seoul, Republic of Korea.

Received: 22 June 2021 Accepted: 5 October 2021

Published online: 01 March 2022

\section{References}

1. Hindricks G, Potpara T, Dagres N, Arbelo E, Bax JJ, Blomstrom-Lundqvist C, Boriani G, Castella M, Dan GA, Dilaveris PE, Fauchier L, Filippatos G, Kalman JM, La Meir M, Lane DA, Lebeau JP, Lettino M, Lip GYH, Pinto FJ, Thomas GN, Valgimigli M, Van Gelder IC, Van Putte BP, Watkins CL, Group ESCSD. 2020 ESC Guidelines for the diagnosis and management of atrial 
fibrillation developed in collaboration with the European Association for Cardio-Thoracic Surgery (EACTS). Eur Heart J. 2021;42:373-498.

2. Kim D, Yang PS, Jang E, Yu HT, Kim TH, Uhm JS, Kim JY, Pak HN, Lee MH, Joung B, Lip GY. 10-year nationwide trends of the incidence, prevalence, and adverse outcomes of non-valvular atrial fibrillation nationwide health insurance data covering the entire Korean population. Am Heart J. 2018;202:20-6.

3. Cox JL, Schuessler RB, Boineau JP. The surgical treatment of atrial fibrillation. I. Summary of the current concepts of the mechanisms of atrial flutter and atrial fibrillation. J Thorac Cardiovasc Surg. 1991;101:402-5.

4. Cox JL, Boineau JP, Schuessler RB, Ferguson TB Jr, Cain ME, Lindsay BD, Corr PB, Kater KM, Lappas DG. Successful surgical treatment of atrial fibrillation. Review and clinical update. JAMA. 1991;266:1976-80.

5. Murashita T, Roberts HG, Wei LM, Rankin JS, Badhwar V. Providing equipoise in the management of patients after surgical ablation with the Cox-Maze IV. J Thorac Cardiovasc Surg. 2018;156:152-3.

6. Haïssaguerre M, Jaïs P, Shah DC, Takahashi A, Hocini M, Quiniou G, Garrigue $\mathrm{S}$, Le Mouroux A, Le Métayer P, Clémenty J. Spontaneous initiation of atrial fibrillation by ectopic beats originating in the pulmonary veins. $\mathrm{N}$ Engl J Med. 1998:339:659-66.

7. Calkins H, Hindricks G, Cappato R, Kim YH, Saad EB, Aguinaga L, Akar JG, Badhwar V, Brugada J, Camm J, Chen PS, Chen SA, Chung MK, Nielsen JC, Curtis AB, Davies DW, Day JD, d'Avila A, de Groot N, Di Biase L, Duytschaever M, Edgerton JR, Ellenbogen KA, Ellinor PT, Ernst S, Fenelon G, Gerstenfeld EP, Haines DE, Haissaguerre M, Helm RH, Hylek E, Jackman WM, Jalife J, Kalman JM, Kautzner J, Kottkamp H, Kuck KH, Kumagai K, Lee R, Lewalter T, Lindsay BD, Macle L, Mansour M, Marchlinski FE, Michaud GF, Nakagawa H, Natale A, Nattel S, Okumura K, Packer D, Pokushalov E, Reynolds MR, Sanders P, Scanavacca M, Schilling R, Tondo C, Tsao HM, Verma A, Wilber DJ, Yamane T. 2017 HRS/EHRA/ECAS/APHRS/SOLAECE expert consensus statement on catheter and surgical ablation of atrial fibrillation. Heart Rhythm. 2017;14:e275-444.

8. Jais P, Haissaguerre M, Shah DC, Chouairi S, Gencel L, Hocini M, Clementy J. A focal source of atrial fibrillation treated by discrete radiofrequency ablation. Circulation. 1997:95:572-6.

9. Drewitz I, Steven D, Lutomsky B, Servatius H, Willems S, RostockT. Persistent, isolated pulmonary vein re-entry: inducibility, entrainment, and overdrive termination of a sustained tachycardia within an isolated pulmonary vein. Europace. 2008;10:261-4.

10. Shah D, Haissaguerre M, Jais $P$, Hocini M. Nonpulmonary vein foci: do they exist? Pacing Clin Electrophysiol. 2003;26:1631-5.

11. Di Biase L, Burkhardt JD, Mohanty P, Sanchez J, Mohanty S, Horton R, Gallinghouse GJ, Bailey SM, Zagrodzky JD, Santangeli P, Hao S, Hongo R, Beheiry S, Themistoclakis S, Bonso A, Rossillo A, Corrado A, Raviele A, Al-Ahmad A, Wang P, Cummings JE, Schweikert RA, Pelargonio G, Dello Russo A, Casella M, Santarelli P, Lewis WR, Natale A. Left atrial appendage: an underrecognized trigger site of atrial fibrillation. Circulation. 2010;122:109-18.

12. Berger WR, Meulendijks ER, Limpens J, van den Berg NWE, Neefs J, Driessen AHG, Krul SPJ, van Boven WJP, de Groot JR. Persistent atrial fibrillation: a systematic review and meta-analysis of invasive strategies. Int J Cardiol. 2019;278:137-43.

13. Jeong DS, Jeong JH, Park PW, Lee YT, Park SJ, Kim JS, On YK. A hybrid procedure for atrial fibrillation using total thoracoscopic ablation and post-procedural electrophysiological confirmation of ablation lines. Korean Circ J. 2013;43:422-5.

14. Hwang JK, Jeong DS, Gwag HB, Park KM, Ahn J, Carriere K, Park SJ, Kim JS, On YK. Staged hybrid procedure versus radiofrequency catheter ablation in the treatment of atrial fibrillation. PLOS ONE. 2018;13:e0205431.

15. Krul SP, Driessen AH, Zwinderman AH, van Boven WJ, Wilde AA, de Bakker $J M$, de Groot JR. Navigating the mini-maze: systematic review of the first results and progress of minimally-invasive surgery in the treatment of atrial fibrillation. Int J Cardiol. 2013;166:132-40.

16. Boersma LV, Castella M, van Boven W, Berruezo A, Yilmaz A, Nadal M, Sandoval E, Calvo N, Brugada J, Kelder J, Wijffels M, Mont L. Atrial fibrillation catheter ablation versus surgical ablation treatment (FAST): a 2-center randomized clinical trial. Circulation. 2012;125:23-30.

17. Castellá M, Kotecha D, van Laar C, Wintgens L, Castillo Y, Kelder J, Aragon D, Nuñez M, Sandoval E, Casellas A, Mont L, van Boven WJ, Boersma LVA, van Putte BP. Thoracoscopic vs catheter ablation for atrial fibrillation: long-term follow-up of the FAST randomized trial. Europace. 2019;21:746-53.

18. van Laar C, Kelder J, van Putte BP. The totally thoracoscopic maze procedure for the treatment of atrial fibrillation. Interact Cardiovasc Thorac Surg. 2017;24:102-11.

19. Calkins H, Kuck KH, Cappato R, Brugada J, Camm AJ, Chen SA, Crijns HJ, Damiano RJ Jr, Davies DW, DiMarco J, Edgerton J, Ellenbogen K, Ezekowitz $M D$, Haines DE, Haissaguerre M, Hindricks G, lesaka Y, Jackman W, Jalife J, Jais P, Kalman J, Keane D, Kim YH, Kirchhof P, Klein G, Kottkamp H, Kumagai K, Lindsay BD, Mansour M, Marchlinski FE, McCarthy PM, Mont JL, Morady F, Nademanee K, Nakagawa H, Natale A, Nattel S, Packer DL, Pappone C, Prystowsky E, Raviele A, Reddy V, Ruskin JN, Shemin RJ, Tsao HM, Wilber D. 2012 HRS/EHRA/ECAS Expert Consensus Statement on Catheter and Surgical Ablation of Atrial Fibrillation: recommendations for patient selection, procedural techniques, patient management and follow-up, definitions, endpoints, and research trial design. Europace. 2012;14:528-606

20. Kim HJ, Kim JS, Kim TS. Epicardial thoracoscopic ablation versus endocardial catheter ablation for management of atrial fibrillation: a systematic review and meta-analysis. Interact Cardiovasc Thorac Surg. 2016;22:729-37.

21. Phan K, Phan S, Thiagalingam A, Medi C, Yan TD. Thoracoscopic surgical ablation versus catheter ablation for atrial fibrillation. Eur J Cardiothorac Surg. 2016;49:1044-51.

22. Lim SK, Kim JY, On YK, Jeong DS. Mid-term results of totally thoracoscopic ablation in patients with recurrent atrial fibrillation after catheter ablation Korean J Thorac Cardiovasc Surg. 2020:53:270-6.

23. Nanthakumar K, Plumb VJ, Epstein AE, Veenhuyzen GD, Link D, Kay GN. Resumption of electrical conduction in previously isolated pulmonary veins: rationale for a different strategy? Circulation. 2004;109:1226-9.

24. Choi MS, On YK, Jeong DS, Park KM, Park SJ, Kim JS, Carriere KC. Usefulness of postprocedural electrophysiological confirmation upon totally thoracoscopic ablation in persistent atrial fibrillation. Am J Cardiol. 2020;125:1054-62.

25. de Asmundis C, Chierchia GB, Mugnai G, Van Loo I, Nijs J, Czapla J, Conte $G$, Velagic V, Rodrigues Mañero M, Ciconte G, Ströker E, Umbrain V, Poelaert J, Brugada P, La Meir M. Midterm clinical outcomes of concomitant thoracoscopic epicardial and transcatheter endocardial ablation for persistent and long-standing persistent atrial fibrillation: a single-centre experience. Europace. 2017;19:58-65.

26. Mahapatra S, LaPar DJ, Kamath S, Payne J, Bilchick KC, Mangrum JM, Ailawadi G. Initial experience of sequential surgical epicardial-catheter endocardial ablation for persistent and long-standing persistent atrial fibrillation with long-term follow-up. Ann Thorac Surg. 2011;91:1890-8.

27. Witkowska A, Suwalski P. Insights from advancements and pathbreaking research on the minimally invasive treatment of atrial fibrillation. J Thorac Dis. 2021;13:2000-9.

28. Gersak B, Pernat A, Robic B, Sinkovec M. Low rate of atrial fibrillation recurrence verified by implantable loop recorder monitoring following a convergent epicardial and endocardial ablation of atrial fibrillation. J Cardiovasc Electrophysiol. 2012;23:1059-66.

29. Geršak B, Zembala MO, Müller D, Folliguet T, Jan M, Kowalski O, Erler S, Bars C, Robic B, Filipiak K, Wimmer-Greinecker G. European experience of the convergent atrial fibrillation procedure: multicenter outcomes in consecutive patients. J Thorac Cardiovasc Surg. 2014;147:1411-6.

30. Zhang J, Sun H, He K, Gu J, Zheng R, Shao Y. Hybrid ablation versus transcatheter ablation for atrial fibrillation: a meta-analysis. Medicine (Baltimore). 2019:98:e14053.

31. van der Heijden CAJ, Vroomen M, Luermans JG, Vos R, Crijns H, Gelsomino S, La Meir M, Pison L, Maesen B. Hybrid versus catheter ablation in patients with persistent and longstanding persistent atrial fibrillation: a systematic review and meta-analysist. Eur J Cardiothorac Surg. 2019;56:433-43.

32. Lapenna E, Cireddu M, Nisi T, Ruggeri S, Del Forno B, Monaco F, Bargagna M, D’Angelo G, Bisceglia C, Gulletta S, Agricola E, Castiglioni A, Alfieri O, De Bonis M, Della BP. Heart-team hybrid approach to persistent atrial fibrillation with dilated atria: the added value of continuous rhythm monitoring. Eur J Cardiothorac Surg. 2021;60:222-30.

33. Osmancik P, Budera P, Zdarska J, Herman D, Petr R, Straka Z. Electrophysiological findings after surgical thoracoscopic atrial fibrillation ablation. Heart Rhythm. 2016;13:1246-52. 
34. Gwag HB, Jeong DS, Hwang JK, Park SJ, On YK, Kim JS, Park KM. Characteristics of symptomatic recurrent tachyarrhythmia after thoracoscopic ablation for persistent atrial fibrillation. Pacing Clin Electrophysiol. 2019:42:686-93.

35. Tan C, Zeng LJ, Shi HF, Tian Y, Ma N, Liu H, Li SC, Hu XH, Mei J, Liu XP. Intraprocedural arrhythmia termination as an end point for hybrid ablation in patients with long-standing persistent atrial fibrillation: a 2-year follow-up study. Interact Cardiovasc Thorac Surg. 2021;33:43-50.

36. Kress DC, Erickson L, Mengesha TW, Krum D, Sra J. Characterizing recurrence following hybrid ablation in patients with persistent atrial fibrillation. J Patient Cent Res Rev. 2020;7:227-38.

37. Romero J, Di Biase L, Mohanty S, Trivedi C, Patel K, Parides M, Alviz I, Diaz JC, Natale V, Sanchez J, Della Rocca DG, Yang R, Mohanty P, Gianni C, Horton R, Burkhardt D, Al-Ahmad A, Lakkireddy D, Natale A. Long-term outcomes of left atrial appendage electrical isolation in patients with nonparoxysmal atrial fibrillation: a propensity score-matched analysis. Circ Arrhythm Electrophysiol. 2020;13:e008390

38. Badhwar V, Rankin JS, Damiano RJ Jr, Gillinov AM, Bakaeen FG, Edgerton JR, Philpott JM, McCarthy PM, Bolling SF, Roberts HG, Thourani VH, Suri RM, Shemin RJ, Firestone S, Ad N. The society of thoracic surgeons 2017 clinical practice guidelines for the surgical treatment of atrial fibrillation. Ann Thorac Surg. 2017;103:329-41.

39. Ni B, Wang Z, Gu W, Li M, Chen M, Lip GYH, Shao Y. Thoracoscopic left atrial appendage excision plus ablation for atrial fibrillation to prevent stroke. Semin Thorac Cardiovasc Surg. 2021;33:61-7.

40. Whitlock RP, Belley-Cote EP, Paparella D, Healey JS, Brady K, Sharma M, Reents W, Budera P, Baddour AJ, Fila P, Devereaux PJ, BogachevProkophiev A, Boening A, Teoh KHT, Tagarakis GI, Slaughter MS, Royse AG, McGuinness S, Alings M, Punjabi PP, Mazer CD, Folkeringa RJ, Colli A Avezum Á, Nakamya J, Balasubramanian K, Vincent J, Voisine P, Lamy A, Yusuf S and Connolly SJ. Left atrial appendage occlusion during cardiac surgery to prevent stroke. N Engl J Med. 2021.

41. Ohtsuka T, Nonaka T, Hisagi M, Ninomiya M, Masukawa A, Ota T. Thoracoscopic stapler-and-loop technique for left atrial appendage closure in nonvalvular atrial fibrillation: Mid-term outcomes in 201 patients. Heart Rhythm. 2018;15:1314-20

42. Badhwar N, Al-Dosari G, Dukes J, Lee RJ. Subxiphoid hybrid approach for epicardial/endocardial ablation and LAA exclusion in patients with persistent and longstanding atrial fibrillation. J Atr Fibrillation. 2018;11:2014.

\section{Publisher's Note}

Springer Nature remains neutral with regard to jurisdictional claims in published maps and institutional affiliations.

Ready to submit your research? Choose BMC and benefit from:

- fast, convenient online submission

- thorough peer review by experienced researchers in your field

- rapid publication on acceptance

- support for research data, including large and complex data types

- gold Open Access which fosters wider collaboration and increased citations

- maximum visibility for your research: over $100 \mathrm{M}$ website views per year

At BMC, research is always in progress.

Learn more biomedcentral.com/submissions 